\title{
O SETOR EMPRESARIAL E A SUSTENTABILIDADE NO BRASIL
}

\section{Martha Macedo de Lima Barata, D.Sc.}

\section{RESUMO}

A resposta do setor empresarial brasileiro ao desafio de produzir bens e prestar serviços ao mesmo tempo em que contribui para a manutenção da qualidade ambiental passou por grandes transformações no final da década passada. Inicialmente, este atendia às diretrizes impostas pelo poder público e às demandas compulsórias da sociedade. Atualmente, percebe-se ser crescente a adoção de iniciativas empresariais voluntárias para a melhoria do desempenho ambiental. Neste artigo, serão apresentados e avaliados os elementos indutores desta recente mudança e, em seguida, será feita uma breve apresentação da evolução da resposta do setor empresarial brasileiro a este novo desafio a ele colocado. Por fim, serão apontadas novas estratégias a serem implantadas para que empresas brasileiras sejam geridas com foco na sustentabilidade empresarial e do país.

Palavras-chave: Desempenho ambiental. Empresas brasileiras. Sustentabilidade.

\begin{abstract}
The response from Brazilian companies to the challenge of being productive while contributing to the maintenance of the environmental quality went through great transformation during the end of the last decade. At first, they used to attend only the directions from the government or the demands from the society. Nowadays, the adoption of voluntary business initiatives for better environmental performance has been increasing substantially. In this article there are going to be presented and evaluated the inductive issues of this recent change and, subsequently, a brief presentation showing the evolution of Brazilian companies response to this new challenge will be made. Finally, there are going to be pointed out new strategies to be settled so that Brazilian companies can be managed with focus on both company and country's sustainability.
\end{abstract}

Keywords: Environmental performance. Brazilian companies. Sustainability 


\section{INTRODUÇÃO}

A constatação de que a capacidade assimilativa dos ecossistemas e da regeneração dos recursos naturais ocorria a taxas incompatíveis com o desgaste imposto à natureza, inspirou 0 surgimento de um novo conceito de desenvolvimento também conhecido como desenvolvimento sustentável, que foi popularizado e definido pela Comissão Mundial Sobre Meio Ambiente e Desenvolvimento (1988), como sendo um processo de transformação no qual a exploração dos recursos, a direção dos investimentos, a orientação do desenvolvimento tecnológico e as mudanças institucionais se harmonizam de modo a contribuir para o bemestar social no presente e no futuro.

O desenvolvimento sustentável coloca o setor empresarial em foco como ator essencial para seu alcance. Ele impõe aos formuladores de políticas públicas, a tarefa de adotar medidas que induzam o setor empresarial a estabelecer metas que estejam inseridas neste novo conceito de desenvolvimento, em que se busca o incremento e/ou a manutenção da produtividade, acompanhada de indicadores de justiça social e de qualidade no processo produtivo, na prestação de serviço, no produto e nas condições ambientais (BARATA,1995).

A resposta do setor empresarial brasileiro a este novo desafio passou por grandes transformações no final da década passada. No início, este atendia às diretrizes impostas pelo poder público, mas atualmente, percebe-se ser crescente a adoção de iniciativas empresariais "voluntárias", bem como a proposição de diretrizes que têm como reflexo a melhoria do desempenho ambiental e social empresarial.

Neste capítulo apresentaremos e avaliaremos os elementos indutores desta recente mudança e em seguida, faremos uma breve apresentação da evolução da resposta do setor empresarial brasileiro a este novo desafio a ele colocado. Por fim, apontaremos novos desafios a serem vencidos para que empresas brasileiras sejam geridas com foco na sustentabilidade empresarial e do País.

Destacamos, para melhor entendimento deste capítulo, que:

- desenvolvimento sustentável e sustentabilidade do País são conceitos sinônimos e que;

- sustentabilidade empresarial corresponde a habilidade da empresa manter-se competitiva e rentável ao longo do tempo, através da oferta de produtos e/ou serviços com qualidade e preço compatíveis com o mercado, e da justa remuneração de sua força de trabalho, investidores e/ou proprietários.

\section{COMPATIBILIDADE ENTRE DESENVOLVIMENTO SUSTENTÁVEL E SUSTENTABILIDADE EMPRESARIAL}

0 debate acadêmico e político-institucional, intensificado na década de 70 , conduziu à aspiração pelo desenvolvimento sustentável. Dentro das definições deste conceito, a natureza é um fator de produção relevante a ser considerado, de modo que a preservação e proteção ambiental passaram a ser condicionantes para a construção de uma "sociedade justa" ao longo do tempo. Numa visão humanista e universalista, Salama (1999, p.75) apresenta que a "sociedade justa" possibilita o atendimento das necessidades básicas universais, comuns aos homens de diferentes culturas e civilizações: alimentar-se, tratar-se, conhecer, mas também agir.

As empresas sempre exerceram papel fundamental no desenvolvimento econômico e social 
de um país (ou região), pois são elas que produzem os bens e serviços de que a sociedade necessita. Entretanto, para que elas também contribuam para o desenvolvimento sustentável, espera-se que elas não sejam mais apenas fornecedoras de produtos, serviços e empregos; mas que também evitem degradar o ambiente e propiciem a construção da "sociedade justa". Mas, será que esta nova postura esperada das empresas é condizente com a sustentabilidade empresarial e com as expectativas de proprietários, acionistas e gestores de empresas?

A compatíbilidade entre o desenvolvimento sustentável e a sustentabilidade empresarial será factível se houver adoção de estratégias empresariais que possibilitem que a empresa se mantenha competitiva, rentável, e proteja o ambiente, além de impulsionar a uma melhoria na qualidade de vida de agentes sociais com ela envolvidos direta e indiretamente.

Jared Diamond, célebre estudioso da biologia evolutiva e da biogeografia; em estudo onde procurou identificar os elementos causadores do "colapso" social, realizou análise de experiências vividas por sociedades que após terem vivido seu momento de "glória/riqueza", passaram ao declínio. Este estudo mostrou também a relevância do ambiente institucional e a participação de agentes do governo e da sociedade civil para que proprietários, acionistas e gestores de empresas atuem com responsabilidade ambiental.

Seu estudo apresenta que: (1) as grandes empresas, dependendo da circunstância, podem de fato maximizar os seus lucros, ao menos no curto prazo, degradando o ambiente; (2) quando a regulamentação do governo é efetiva e o público está ambientalmente consciente, percebe-se que a rentabilidade de grandes empresas ambientalmente limpas pode superar a das "sujas", mas o oposto também pode ser verdade caso a regulamentação seja ineficaz e o público omisso quanto a este quesito. Diamond (2005; p. 577) afirma que:

É fácil e barato culpar uma empresa por se locupletar ferindo outras pessoas. Mas é pouco provável que apenas culpar empresa venha a mudar algo. Tal atitude ignora o fato de que as empresas não são instituições de caridade e, sim negócios que visam lucro, e que as empresas privadas têm a obrigação de maximizar os lucros de seus acionistas, desde que o façam de modo legal.

0 autor justifica esta afirmação através da apresentação que indica que as leis americanas tornam os diretores de empresas responsáveis pelo chamado "abuso de responsabilidade fiduciária" se administrarem suas empresas de modo a reduzir seus lucros. Neste mesmo estudo, o autor aqui citado apresenta o caso do fabricante de carros Henry Ford, que ao aumentar voluntariamente o salário mínimo de seus trabalhadores, foi processado com sucesso por acionistas em 1919, uma vez que o tribunal declarou que, embora os sentimentos humanitários de Ford quanto aos seus funcionários fossem louváveis, seu negócio existia para dar lucro aos acionistas.

0 autor atribui responsabilidade ao público por criar condições que permitam uma empresa lucrar através do seu prejuízo. A longo prazo, é o público, seja diretamente ou através de seus políticos, que tem o poder de tornar não lucrativa e ilegal as políticas ambientais empresariais destrutivas e fazer políticas ambientalmente sustentáveis (DIAMOND, 2005; p. 578). Esta afirmação nos leva a dois questionamentos:

1. Sabe-se que os impactos sociais e ambientais provenientes de uma atividade econômica podem ter abrangência local, regional (contaminação de lençol freático, rios,etc.) ou global (aquecimento global do planeta). Sendo assim, a gestão ambiental das empresas será diferenciada levando-se em consideração o setor, local, ambiente institucional e a abrangência 
do mercado em que opera?

2. Como e qual público poderia influenciar o desempenho de empresas que contribuem para a degradação ambiental e social, regional ou global? Respondendo ao primeiro questionamento, observa-se que o fluxo de informações e de recursos financeiros migra em tempo real no mundo globalizado em que se vive nos dias atuais (CAPRA, 2006). Assim, o comportamento de empresas que atuam globalmente, tais como as empresas transnacionais, não depende apenas da regulamentação e do público local, pois acidentes de maior proporção, bem como, a iminência das empresas incorrerem em passivos ambientais ou de terem sua imagem associada à degradação do ambiente podem rapidamente ser informados a outros públicos.

Essas associações podem trazer conseqüências imediatas na sua rentabilidade e competitividade, fato que independe de onde estejam localizadas. Nesse sentido, a globalização econômica e da informação podem motivar empresas a terem um melhor desempenho ambiental e social, mesmo que as mesmas operem em locais aonde a população e a legislação local não sejam suficientes para tal.

Respondendo ao segundo questionamento, observa-se que o público que poderá influenciar no desempenho social e ambiental de empresas é constituído por sua partes interessadas. Vale lembrar que o conceito de público aqui utilizado está sendo comparado com aquele já aqui descrito por Diamond (2005). Alguns autores usam os termos agentes sociais, atores sociais ou stakeholders como sinônimo de partes interessadas, que podem ser: acionistas, proprietários, força de trabalho, investidores, clientes e fornecedores da empresa; além de comunidade, governo e consumidores sob sua área de influência, bem como organizações não governamentais, dentre outras.

Segundo definição de Edward R. Freeman (1984), partes interessadas são grupos e/ou indivíduos que podem afetar ou serem afetados durante o cumprimento dos objetivos organizacionais da empresa. Autores como Preston \& Post, Freeman \& Gilbert, R. Mitchel, B. Agle \& D. Wood, dentre outros, desenvolveram diferentes formas para a identificação e monitoração das partes interessadas estratégicas para as empresas, cada uma delas apresenta vantagens e desvantagens (LETIERI, apud LIMA, 2006).

A construção de um relacionamento duradouro e consistente com as partes interessadas, permite que a empresa se adapte mais rapidamente às demandas da sociedade. 0 relacionamento entre as empresas e suas partes interessadas deve ser considerado como uma via de mão dupla, em que as empresas influenciam e também são influenciadas por estas. Se, por um lado, as empresas podem ser impelidas a mudar a forma como gerenciam seus negócios diante de um mercado consumidor mais consciente e exigente, por outro, as empresas podem contribuir para a disseminação de práticas responsáveis de gestão à medida que influenciam seus clientes e fornecedores a adotarem práticas contribuintes para a sustentabilidade.

O conhecimento claro e objetivo dos efeitos ambientais, sociais e econômicos da atividade desempenhada pela empresa, são requisitos fundamentais para que a influência do "público" no melhor desempenho empresarial seja efetiva. Entretanto, o conhecimento e as informações sobre o potencial impacto ambiental e social de uma atividade nem sempre coincidem. A melhor forma de resolver o impasse introduzido pela ciência tradicional - que, frente ao conflito de opiniões, foge em direção a um maior reducionismo técnico - é fazer com que a avaliação das informações científicas para a tomada de decisões empresariais seja realizada em um espaço comunicativo, integrado por empresas, cientistas e técnicos e demais partes 
interessadas estratégicas (REIS, 1997).

Uma empresa engajada em identificar e atender respectivas demandas de partes interessadas

é também tida como socialmente responsável. Cabe aqui apresentar um conceito que vem sendo popularizado no País e que pretende apoiar empresas a se manterem sustentáveis, ao mesmo tempo em que contribuem para o desenvolvimento sustentável, que é a Responsabilidade Social (RS) Corporativa. A empresa com RS atende a necessidade de manutenção de sua competitividade e rentabilidade através da construção de um modelo mais justo, calcado na solidariedade, na ética e na sustentabilidade ecológica. Percebe-se, portanto, a existência de forte relação entre RS e esses conceitos; desenvolvimento sustentável e sustentabilidade empresarial, já que se torna inviável a mudança do modelo de desenvolvimento sem a participação e o comprometimento das empresas na construção de um mundo melhor para todos.

O conhecimento por parte das partes interessadas dos impactos ambientais e sociais de determinadas atividades, produtos e serviços, contribuirá para que estas possam exercer influência positiva e atuar em sinergia com as empresas em prol da sustentabilidade do País.

\section{GESTÃO AMBIENTAL EMPRESARIAL VOLUNTÁRIA}

As estratégias e modos de gestão das empresas se harmonizam aos momentos históricos e aos ambientes em que elas se realizam. Para tanto, elas estão em constante mutação adaptando-se ao seu tempo (RODRIGUES, 2005 apud Wood 1990), onde variáveis internas (recursos humanos, financeiros e tecnológicos, dentre outros) e externas (ambiente institucional, regulatório, sócio-econômico, cultural e ambiental) irão influenciar em sua gestão e conseqüente sustentabilidade.

A resposta do setor empresarial ao desafio de contribuir para o desenvolvimento sustentável foi diferenciada ao longo do tempo. Isto é, nos primórdios dos questionamentos sobre o desempenho ambiental das empresas, estas limitavam - se, em alguns casos, a adotar as medidas necessárias para evitar a paralisação de suas atividades ou o recebimento de multas, quando não atuavam em conformidade com os procedimentos e padrões legais. Os requisitos ambientais eram considerados, então, como um fator de incremento de custos de produção e por isto não lhes era imputada a devida importância. Visando atender às exigências dos órgãos competentes, as empresas implantavam tecnologias de controle das emissões no final do processo de produção, que correspondiam na maior parte das vezes, a instalação de caros e sofisticados filtros em suas chaminés e volumosas estações de tratamento dos resíduos líquidos. Este procedimento resultava em altos investimentos e aumento do custo final dos produtos. Desta forma, a responsabilidade corporativa pelas questões ambientais era funcionalmente isolada, restringindo-se em geral, a um único responsável ou unidade dentro da empresa, que tentava convencer as outras unidades a seguirem as normas ambientais. A competitividade e o meio ambiente eram, então, totalmente antagônicos, e as relações entre as indústrias e demais tipos de empresas, os governos e as organizações não-governamentais ambientalistas era de constante confrontação (LEMOS, 2000,p.1).

A ocorrência de acidentes ambientais tais como: o incidente na Allied Chemical Corporation, em Hopewell, Virgínia (EUA), em 1975; a explosão química da Hoffman- La Roche, em Seveso (Itália), em 1976; o vazamento de gases tóxicos numa fábrica de pesticida da Union Carbide em Bhopal (Índia), em 1984; a explosão de um reator nuclear em Chernobyl, na então União Soviética, em 1986; o vazamento de petróleo, em 1990, do navio petroleiro Exxon Valdez e o caso emblemático do Love Canal, no estado de Nova York - um símbolo de contaminação do 
solo por resíduos sólidos enterrados - entre outros; obrigou as empresas a arcarem com gastos elevados em pagamento de indenizações, recuperação dos ambientes danificados e ações para mitigação e controle dos danos. Também houve prejuízo para a imagem das empresas geradoras dos danos ambientais. Frente a esse quadro, empresas com maior potencial poluidor passaram a desenvolver e implantar instrumentos de gestão ambiental voluntários, que contribuíssem para a melhoria do fluxo de informação, interno e externo, propiciassem a redução de risco de incidentes e acidentes ambientais e mitigassem os danos ao ambiente sem reduzir sua competitividade.

Percussora na elaboração de diretrizes para a gestão ambiental voluntária em 1984, a Canadian Chemical Producers Association (CCPA) editou documento para o setor químico denominado Statement of Responsible Care and Guiding Principles, contendo princípios específicos para a gestão responsável do processo de produção em todo o ciclo de vida do produto, dando ênfase à proteção da saúde humana e do meio ambiente, a segurança industrial e do produto. Além de detalhar as iniciativas que as empresas precisam tomar para atender aos princípios do Responsible Care, o documento destaca a necessidade de comprometimento de todos os envolvidos na produção, na distribuição e no recebimento dos produtos das respectivas empresas, assim como da troca permanente de informações com a comunidade vizinha.

A adoção desses princípios em vários países, como EUA, Inglaterra e Brasil, dentre outros, contribuiu para resgatar uma imagem positiva da indústria química perante a opinião pública. Este tipo de ação coordenada, envolvendo um grande número de empresas de um segmento industrial, seria, sob a ótica da gestão ambiental, um importante exemplo de estratégia cooperativa que, devido ao seu caráter pioneiro e a sua abrangência, viriam a ser seguidos por diversos outros setores com elevado potencial poluidor, em especial, pela indústria do petróleo. Posteriormente, com o objetivo de harmonizar globalmente os procedimentos de gestão ambiental empresarial sem privilegiar determinados setores ou países, foram criados, em 1994, no âmbito da International Standard Organization (ISO), grupos de trabalho para o desenvolvimento de normas contendo diretrizes aplicáveis aos diferentes setores produtivos em regiões distintas e que possibilitem uma gestão empresarial com responsabilidade ambiental.

O grupo de normas da Série ISO 14.000 oferece diretrizes para apoiar na gestão ambiental empresarial e para o desenvolvimento de produtos menos degradantes do ambiente. Dentre elas, ressalta-se as normas ISO 14001 e ISO 14004, aprovadas e publicadas em 1996, e posteriormente revisadas e publicadas em nova versão em 2000. Nelas, encontram-se especificados os requisitos gerenciais para estabelecer um Sistema de Gestão Ambiental (SGA) e obter a certificação nos mais diversos tipos de organizações - respeitadas suas especificidades setoriais, geográficas, culturais e econômicas. Dentre essas normas, também estão sistematizados os procedimentos necessários para a definição dos princípios norteadores da política ambiental da empresa e ações necessárias para o seu atendimento e para a contínua melhoria do desempenho ambiental da empresa.

A certificação da empresa pela norma ISO 14001 assegura a todas as partes interessadas da empresa que as práticas gerenciais para a manutenção e melhoria do seu desempenho ambiental se ajustem ao estabelecido na norma, independentemente do setor e/ou local onde a empresa esteja atuando. Em outras palavras, este instrumento propicia a transparência e a unidade no fluxo de informações para o público interno e externo das empresas sobre os procedimentos de gestão ambiental aplicados por elas. 
A relevância deste instrumento pode ser constatada pela quantidade e diversidade de empresas certificadas no mundo. Até 2003, foram concedidas 36.765 certificações, das quais apenas $645(1,7 \%)$ correspondem a empresas situadas na América do Sul. A maior parte delas pertence a países de Europa (18.243) e Ásia (13.410), em cujas sociedades há um maior grau de preocupação ambiental e têm-se desenvolvido tecnologias menos poluentes. (www.inmetro.gov.br; 2005)

Em resposta a necessidade de gerenciar suas atividades considerando a variável ambiental, o setor empresarial estabeleceu o conceito de eco-eficiência, que retrata a abordagem que liga empresários/negócios, meio ambiente e necessidades humanas presentes e futuras. Estabelecido em 1991 no âmbito do Conselho Empresarial Mundial para o Desenvolvimento Sustentável (WBCSD), a eco-eficiência está relacionada a três importantes objetivos:

- Redução do consumo de recursos: através da minimização do uso de energia, materiais, água e solo, e a promoção do re-uso de materiais e da durabilidade dos produtos, além da redução dos desperdícios;

- Redução do impacto na natureza: através da redução de emissões atmosféricas, lançamentos de efluentes e geração de resíduos e de ruídos, dentre outros;

- Aumento da produtividade ou do valor do produto: através do atendimento objetivo, a necessidade dos clientes fornecendo produtos mais flexíveis, funcionais, duráveis e que utilizem a menor quantidade de recursos possível.

Observa-se que o conceito de eco-eficiência traduz a real necessidade de produzir mais com menos recursos, ou seja; não se prioriza a re-utilização ou a reciclagem de materiais, mas sim a redução do consumo dos recursos naturais e do impacto sobre o meio ambiente.

Dentro do conceito de eco-eficiência, destaca-se a iniciativa empresarial do ecodesign , em que os aspectos ambientais são considerados em todos os estágios de desenvolvimento de um produto, colaborando para reduzir o impacto ambiental durante seu ciclo de vida. Isto significa reduzir a geração de resíduos e economizar custos de disposição final. A idéia básica deste modelo é considerar os problemas ambientais na fase de planejamnto do produto e do serviço a ser ofertado.

Outras iniciativas foram desenvolvidas com o intuito de incentivar empresas que contribuam voluntariamente para a sustentabilidade. Assim, a Bolsa de Nova Iorque (Dow Jones) criou, em parceria com a Sam Reserach, um índice especial para negociação de ações de empresas consideradas sustentáveis - Dow Jones Sustainability Index (DJSI). As empresas participantes deste índice são selecionadas a partir de diversos critérios que mostram, dentre outros, seu desempenho ambiental e social. Seguindo a linha do DJSI, a Bolsa de São Paulo também lançou, em 2005, um índice similar; o Índice de Sustentabilidade Empresarial (ISE). Ressalta-se também o movimento recente de institutos, como o GRI (Global Reporting Initiative) no âmbito mundial, o Instituto Ethos de Responsabilidade Social, e o Instituto Brasileiro de Análises Sociais e Econômicas (IBASE) no Brasil, que desenvolveram indicadores para contribuir para que as empresas também avaliem seu desempenho ambiental e social e o relatem às demais partes interessadas. A justificativa para essa "padronização" de indicadores de desempenho é a necessidade de se estabelecer um denominador comum aos relatórios de desempenho anualmente publicados, facilitando desta forma, não somente a sua compreensão, como também a comparação com os indicadores de outras empresas e a comunicação clara de 
suas informações às partes interessadas.

Adicionalmente, empresas pró-ativas que perceberam e investiram para obter melhoria do respectivo desempenho ambiental passaram não apenas a orientar-se para a sustentabilidade, mas também tentaram nortear a sociedade e os governos no mesmo sentido, de modo a manterem sua competitividade no curto e no longo prazo (CAIRNCROSS, 1992).

Concluiu-se que alguns instrumentos que têm contribuído para que empresas insiram voluntariamente a variável ambiental em sua gestão. São eles: o estabelecimento de normas de sistema de gestão ambiental, o desenvolvimento de novas tecnologias e de processos alternativos de produção que contribuem para a redução de custos, pautados no princípio da eco-eficiência, além da oportunidade de criação de novos mercados e do potencial competitivo da empresa.

Enfatiza-se que os instrumentos de gestão ambiental empresarial podem ser considerados voluntários por não serem exigidos através de legislação, mas eles são muitas vezes compulsórios em face de exigências que lhes são impostas por partes interessadas e/ou mercado. Assim, ele será voluntariamente implantado caso o gestor da empresa perceba que ele pode contribuir para:

- Redução de custos: na medida em que a empresa incorpora a variável ambiental através de técnicas e procedimentos que aumentem a eficiência no uso de matériasprimas (recursos naturais), água e energia, por intermédio da não geração e minimização dos resíduos gerados.

- Redução de risco ao negócio: na medida em que incorporam análises de longo prazo na avaliação de seu negócio, empresas antecipam perigos/riscos e adotam, quando cabível, medidas para evitar incidentes, acidentes e situações que possam ser transformadas em gastos futuros que denigram sua imagem.

- Criação de oportunidades: do ponto de vista dos negócios, criar oportunidades significa conquistar novos mercados e manter interesse em inovar (processos, produtos, materiais, tecnologias), aprender, implantar e repassar a terceiros.

- Melhor relacionamento com as partes interessadas: empresas desenvolvem alternativas que as apóiem no atendimento de expectativas de partes interessadas e conseqüentemente no relacionamento com as mesmas (KEEBLE, EAGAR \& MÜLHÄUSER, 2003; apud LIMA, 2006).

Evolução da Contribuição das Empresas no Brasil para a Sustentabilidade A incorporação da variável ambiental na gestão das empresas brasileiras é recente e ainda não está sendo igualmente implantada para todos os setores e regiões, uma vez que a demanda de partes interessadas sobre as empresas pode variar segundo o setor, o mercado e a localização da empresa.

Interessante, porém, é verificar o rápido crescimento da implantação de medidas de controle e de programas de gestão ambiental empresarial no País, além da crescente atuação do segmento empresarial na proteção ao meio ambiente.

Estudo realizado pelo IBGE, aponta que o percentual de investimentos em controle ambiental, com vistas a reduzir ou controlar emissão de poluentes no País, aumentou no 
período compreendido entre 1997 e 2002. Pois, o aumento do número de empresas industriais no País foi de cerca de $26 \%$, e o investimento em controle ambiental representou um crescimento de $75 \%$. A participação do valor total investido em controle ambiental em relação ao valor total das aquisições, produção própria e melhorias de máquina e equipamento industrial, descontado o efeito inflacionário, aumentou de 14\% em 1997, para 19\% em 2002; resultado alavancado pela indústria de transformação que aumentou em 93\% o valor de investimento em controle ambiental. 0 estudo considera os gastos realizados em aquisição de máquinas que já incorporam a concepção de tecnologia limpa, em aquisição de equipamentos, em obras com estações de tratamento e em outros gastos necessários a que os referidos itens entrassem em funcionamento.

É interessante avaliar alguns fatos que influenciaram a variação no investimento setorial em controle ambiental (ver figura 1). Assim, pesquisa realizada por Barata (1995) identificou que, na ocasião, eram poucas as empresas no País que apresentavam programa de gestão ambiental, predominantemente aplicada por empresas transnacionais do setor químico e portanto, os novos investimentos em ativos para controle ambiental deste setor, em 1997 foram inferiores ao dos setores de alimentos e bebidas, refino, celulose e papel e metalurgia básica. Observa-se que as certificações obtidas pelas indústrias de cerveja do País, no ano de 2000, impulsionaram os maiores investimentos em controle ambiental em 1997, conforme resultados da figura 1.

Figura 1: Investimento em controle ambiental na indústria - Brasil 1997 x 2002

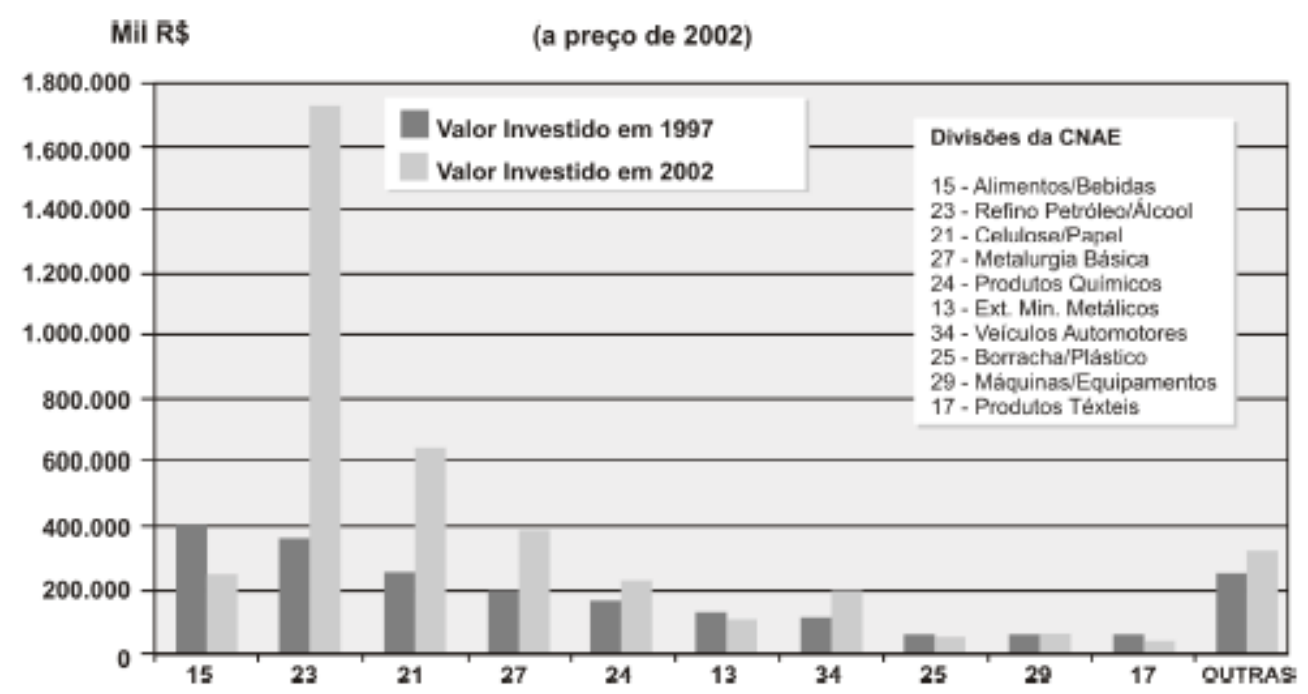

Nota: Valores de 1997 atualizados monetariamente para 2002 pelo índice de preços da Fundação Getúlio Vargas para o segmento de máquinas e equipamentos $(1,5394)$.

Fonte: IBGE, Diretoria de Pesquisas, Coordenação de Indústria, Pesquisa Industrial Anual - Empresa 1997 e 2002

A participação setorial em investimentos em controle ambiental alterou-se em 2002, uma vez que maiores volumes já haviam sido feitos por grandes empresas do setor alimentício e de bebidas. 0 significativo incremento em investimento em controle ambiental por parte das empresas do setor de petróleo e álcool, foi motivado por: (1) regulamentação de legislação mais restritiva, com destaque para as Resoluções CONAMA 23/94, que regulamenta o licenciamento das atividades petrolíferas e para a CONAMA 237/97, que regulamenta os aspectos de licenciamento ambiental estabelecidos na Política Nacional de Meio Ambiente; estabelecimento de escritório específico para licenciar empresas do setor; 
(2)ocorrência de acidentes com impacto na mídia (ex: acidente na Bahia de Guanabara em 2000 e na refinaria do Paraná) e nos gastos das empresas com compensação, multa e correção dos danos ocasionados; (3) interesse em certificação pela ISO 14001 e (4) pretensão de empresa nacional do setor por abrir seu capital no mercado internacional.

Os serviços ambientais tais como: tratamento e disposição de resíduos industriais e dos municipais, o transporte e o gerenciamento, o tratamento de efluentes, as análises laboratoriais e as atividades de remediação de área contaminada, ofertaram emprego direto a 14.400 pessoas e geraram receita de um bilhão e meio de reais em 2005, valor 15 \% superior ao realizado em 2004. Este resultado mostra que os serviços ambientais também contribuem para o Produto Interno Bruto (PIB) do País, ainda que em pequena proporção. Observam-se no País, por meio deste mesmo estudo, uma tendência no aumento de prestação de serviços ambientais pautados no princípio da eco-eficiência, tais como, o co-processamento e a reciclagem dos resíduos (ABETRE, 2006).

A aprovação das normas de gestão ambiental no âmbito do Brasil, adicionada ao interesse pela participação no mercado internacional, têm contribuído para que algumas empresas que atuam no Brasil mudem sua postura em relação à questão ambiental. Desde a aprovação da norma ISO 14001, foram certificadas pelo Instituto Nacional de Metrologia, Normalização e Qualidade (INMETRO) no Brasil, 1.031 empresas em 2007; sendo que até o ano de 2000, tinham sido certificadas apenas 198 empresas, e é interessante observar que a maior parte das empresas certificadas até o ano de 2000, tinha sua atuação vinculada ao mercado internacional; tais como empresas do setor de celulose, mineração, siderurgia, petróleo e gás e bebida, ou eram empresas multinacionais; tais como as de alimento e do setor automotivo. É interessante observar que nos anos subseqüentes houve uma maior diversificação nas certificações que foram concedidas a indústrias de transformação, empresas de construção, transporte e tratamento de resíduos, dentre outras; pertencentes à cadeia produtiva das empresas anteriormente certificadas (www.inmetro.gov.br, 2007). Ressalta-se que estes números não congregam o universo de empresas certificadas no Brasil, uma vez que estas podem ser certificadas por organismos de acreditação externos.

Os itens da norma que têm contribuído positivamente para que empresas certificadas exerçam influência para a melhoria do desempenho de empresas que atuam em sua cadeia produtiva no País são: a necessidade da empresa avaliar o desempenho ambiental de sua fornecedora e atender a legislação ambiental; a necessidade de divulgar sua política ambiental interna e externamente, e a ampliação de programas de comunicação externa e interna que contribuam para a disseminação da relevância social da preservação e proteção ambiental.

O projeto de produção mais limpa (PmaisL) iniciado em 1995, pelo Centro Nacional de Tecnologias Limpas do SENAI-RS (CNTL-RS), através de convênio estabelecido com o Programa das Nações Unidas para o Meio Ambiente (UNEP) e a Organização das Nações Unidas para o Desenvolvimento Industrial (UNIDO), também tem contribuído para a melhoria do desempenho ambiental empresarial no País.

A metodologia do PmaisL propõe que, após a realização do diagnóstico da qualidade da gestão ambiental na empresa, dos equipamentos, das técnicas existentes para o controle, redução na fonte e monitoramento de emissões (gasosas, líquidas e sólidas) existentes além da capacitação da força de trabalho, apresentem alternativas que sejam identificadas e avaliadas para: reduzir consumo de recursos físicos (energia, água e matérias primas); 
solucionar deficiências diagnosticadas e identificar oportunidades para melhorar o desempenho ambiental da empresa. A seleção das alternativas considerará o respectivo benefício financeiro para a empresa.(BARATA, 2006). Assim, na primeira fase da implantação do PmaisL no País, a metodologia foi aplicada em onze pequenas e médias empresas que investiram um total de $\mathrm{R} \$ 220$ mil e obtiveram ganhos financeiros da ordem de R\$ 497 mil/ano; em face da redução na geração de 97 ton/ano de resíduos perigosos, bem como no consumo de matéria prima (120 ton/ano), de energia (1660 Mwh/ano) e de água (120 mil m3/ano). As soluções propostas nem sempre envolveram investimentos e, em muitos casos, representaram apenas mudanças no processo operacional da empresa e treinamento dos funcionários (BARATA, 2006). Os resultados alcançados nesta primeira fase de implantação do PmaisL contribuíram para a consolidação da Rede Brasileira de Produção Mais Limpa, composta pelo SEBRAE Nacional, Centro Empresarial Brasileiro para o Desenvolvimento Sustentável (CBEDS), o CNTL-RS, e contou com o apoio dos núcleos regionais do SEBRAE bem como o incentivo de instituições regionais de apoio à indústria e ao comércio, de ensino e pesquisa e também de organismos de financiamento.

A Rede Brasileira de Produção Mais Limpa foi iniciada no País em 1999, e ampliada em 2002. Voltado para a questão da eficiência econômica e ambiental da empresa, o programa no País apresentou resultados em redução de gastos financeiros acoplados a benefícios ambientais provenientes da redução anual do consumo de matérias primas, água e energia elétrica; além de redução de impactos ambientais, contribuindo assim para a ampliação de usuários da rede no País. Casos de sucesso em sua implantação podem ser encontrados nos sites do SEBRAE, CETESB e CEBEDS, dentre outros; onde fica caracterizado o incentivo, a inovação tecnológica e gerencial em empresas que implantam o programa, uma vez que as soluções para a melhoria do desempenho ambiental ao menor custo possível, são avaliadas e adotadas designadamente para cada empresa que o implanta.

A PmaisL não está vinculada a certificação através da ISO 14001, e a despeito de serem programas distintos, ambos têm como objetivo o melhor desempenho ambiental das empresas, pondendo ser implantados conjuntamente. Vinculado ao conceito de ecoeficiência empresarial, o PmaisL visa a maior eficiência na alocação dos recursos na empresa e a redução da poluição gerada por suas atividades. A ISO14001 orienta empresas para que estas desenvolvam um sistema de gestão que contribua para a melhoria de seu desempenho ambiental, e que possa ser conhecido por partes interessadas.

Nada impede que ambos os programas, que podem ser complementares, sejam implantados por uma mesma empresa. Neste contexto, empresas brasileiras do setor público iniciam a implantação da Agenda Ambiental na Administração Pública (A3P). Alguns dos procedimentos propostos na A3P são semelhantes aos da norma ISO 14001, mas sua maior ênfase está na diminuição do desperdício, através dos 3R's, isto é: reduzir, reciclar e reutilizar a quantidade de resíduos gerados, sobretudo nos escritórios.

Criada no final de 1999 pelo Ministério do Meio Ambiente (MMA) e oficializada pela Portaria № 510/2002, a A3P pretende instaurar um processo de construção de uma nova cultura institucional na administração pública, visando a mobilização dos servidores para a otimização dos recursos para o combate ao desperdício e para a busca de uma melhor qualidade do ambiente de trabalho. Visa também colocar as empresas em sintonia com a concepção de eco-eficiência, incluindo critérios socioambientais nos investimentos, compras e contratações de serviços dos órgãos governamentais. 0 site do MMA apresenta 
a relação de empresas públicas que estão implantando a A3P, acompanhada de respectivos resultados (www.mma.gov.br, 2007).

Percebe-se também incentivos ao eco-design no País por parte de empresas como por exemplo: a Natura e a Kibon, que distribuem seus produtos em embalagens reaproveitáveis pelo consumidor de seus produtos; a Xerox ou da Tetrapack, que mantém um programa para coleta e reaproveitamento de parte do produto; empresas vinculadas ao setor de eletroeletrônicos, automóveis, farmacêuticos e computadores, que estudam meios para que seus produtos sejam recicláveis ou re-utilizados; o programa de fomento a redução no consumo energético implantado no âmbito do PROCEL, que tem contribuído para que consumidores adquiram apenas eletrodomésticos que tenham o selo do mesmo e, portanto, sejam mais eficientes no consumo energético. Ressalta-se também a intensificação recente em algumas cidades do País, de programas orientados para a construção sustentável; isto é, orientados para que os materiais usados na construção civil (casas, edifícios, shoppings,etc.) sejam eficientes no consumo energético, de água e de materiais, dentre outros.

Destaque também deve ser dado aos programas e institutos que têm contribuído para difundir a atuação ambiental e/ou socialmente responsável das empresas no País, tais como a Fundação Abrinq (1990), o Grupo de Institutos, Fundações e Empresas (GIFE, em 1995), o Conselho Empresarial Brasileiro para o Desenvolvimento Sustentável (CEBDS, em 1997), o Instituto Ethos (1998) e o Instituto para o Desenvolvimento do Investimento Social (IDIS, em 1999).

Objetivando fortalecer a prática de Responsabilidade Social no âmbito empresarial, o Instituto Ethos desenvolveu uma série de indicadores que avaliam o estágio em que as empresas se encontram em relação à sua atuação social responsável. Atualmente, o instituto possui mais de 1000 empresas associadas (ver gráfico 1). 0 faturamento anual dessas empresas representa cerca de $30 \%$ do PIB brasileiro e a quantidade de empregos gerados por elas chega a 1 milhão de postos de trabalho (SOUZA,2006).

Gráfico 1: Empresas Associadas ao Instituto Ethos

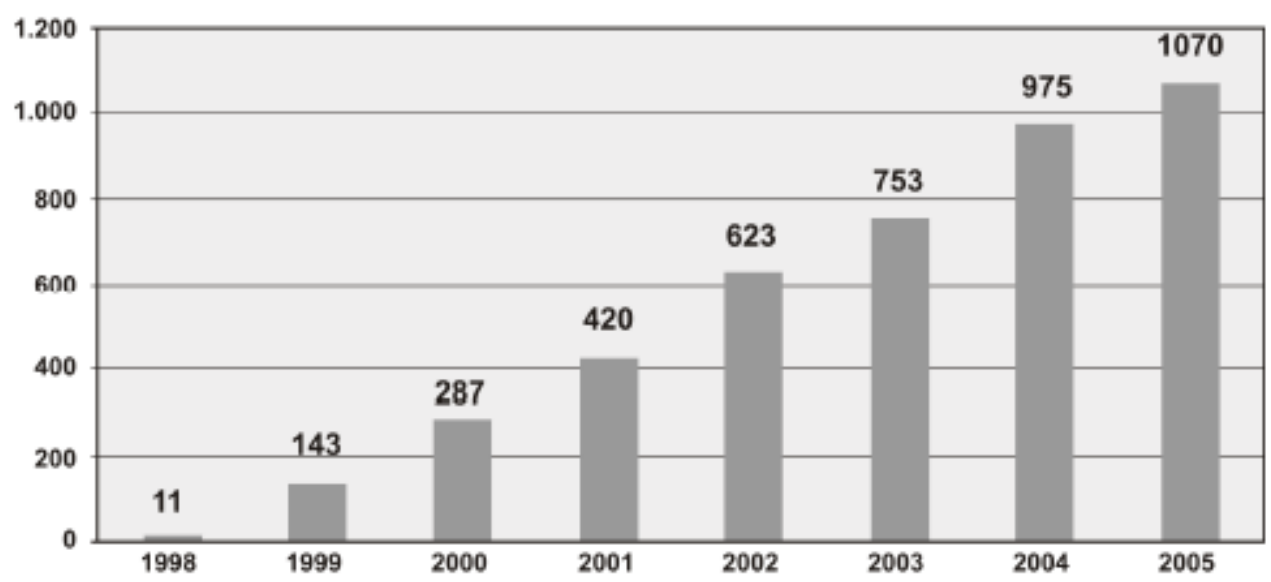

Fonte: Instituto Ethos em http://www.ethos.org.br , 2006; apud Souza, 2006

Desde 2000, a revista Exame publica o Guia de Boa Cidadania Corporativa. Neste guia, são escolhidas empresas-modelo em boas práticas de responsabilidade social. Os critérios analisados seguem o modelo do questionário do Instituto Ethos, são eles: 1 . Valores e Transparência; 2. Funcionários e Público Interno; 3. Meio Ambiente; 4. Fornecedores; 5. 
Consumidores e Clientes; 6.Comunidade; 7. Governo e Sociedade. Empresas que se destacam nos sete critérios avaliados são premiadas. A Natura foi premiada todos os anos e a Belgo Mineira, o Mc Donald's, a Perdigão, o Serasa, a 3M e a CPFL, foram premiadas por pelo menos três anos (SOUZA, 2006).

Mesmo não tendo números para evidenciar a percepção empírica, constata-se que a veiculação de resultados alcançados por empresas que aplicam gestão ambiental na mídia eletrônica e escrita, experimentou expressivo aumento nos últimos dez anos. Fato semelhante ocorreu no ensino onde o número de cursos universitários ou de eventos científicos que abordam a temática ambiental cresceu significativamente.

0 interesse de empresas em ter suas ações no mercado internacional também tem contribuído para a ampliação de ações de responsabilidade ambiental e social das mesmas. A despeito de ser ainda pouco significativo, é relevante apresentar que empresas brasileiras distribuidoras de energia, de exploração e produção de petróleo, bem como do setor financeiro, compõem o Dow Jones Sustainability Group Indexes - (DJSGI). Lançado em setembro de 1999, este é o primeiro índice global que incorpora o desempenho das empresas líderes no mundo em sustentabilidade. O DJSGI atende ao crescente interesse dos investidores nas companhias comprometidas com os princípios da sustentabilidade. Estes princípios - tecnologia inovativa, governança corporativa, relações com partes interessadas, liderança industrial e bem estar social - tornam-se fatores cruciais em tomadas de decisão de investimentos. A integridade da avaliação sustentável corporativa e o cálculo dos índices asseguram que o DJSGI seja independente, confiável, passível de investimento que faz dele uma plataforma para fundos e derivativos baseados em índices. No período compreendido entre 1993 a 2006, o índice obteve desempenho superior ao índice geral da Bolsa de Nova Iorque, tendo alcançado uma valorização de $138 \%$ enquanto o MSCI (índice de referência global de rentabilidade da Bolsa de Nova Iorque) subiu apenas 75\%, uma diferença de 63 pontos percentuais (http://www.sustainabilityindex.com , 2006).

Semelhante variação ainda não ocorreu com o Índice de Sustentabilidade Empresarial lançado pela Bolsa de Valores do Estado de São Paulo (BOVESPA) em 2005, mas este já desperta interesse de empresas que têm sua gestão voltada para a sustentabilidade. 0 extenso questionárioa a ser preenchido por empresas que pretendam se se incorporar a este seleto grupo o mantém aind arestrito.

Destaque também deve ser dado à adesão de empresas/novos empreendimentos do País ao mercado de crédito de carbono, através da redução de suas emissões ou de sua captura. Dentre os exemplos apresentados, destaca-se o da Usina Verde, primeira empresa no mundo certificada que pretende usar o gás metano liberado pelo "lixo" para a geração de energia elétrica e a recente iniciativa no Rio de Janeiro de coletar óleo (de uso de estabelecimentos comerciais de produção de alimentos - restaurantes), usado para o transporte de ônibus público; substituindo assim o óleo diesel pelo biodiesel.

Percebe-se pelo o que aqui foi apresentado que, além dos instrumentos de gestão ambiental pública, outros instrumentos estão sendo desenvolvidos e implantados para apoiar empresas a serem "voluntariamente" sustentáveis e a contribuir para o desenvolvimento sustentável do País. Não obstante, muito ainda há que ser feito.

Apesar da aceleração na melhoria do desempenho ambiental e social de algumas empresas em resposta aos instrumentos apresentados, esta ainda está restrita a alguns setores 
produtivos e não está igualmente estabelecida em todas as regiões do País. Os números apresentados ao longo deste capítulo mostram que mesmo crescentes, ainda são restritos os investimentos e os casos de sucesso em melhoria do desempenho ambiental e social empresarial. Estes podem e devem ser ampliados ao longo dos próximos anos para que sejam capazes de contribuir efetivamente para o desenvolvimento sustentável do País. Contudo, ressalta-se ser relevante a efetiva participação das partes interessadas: governo e comunidade, para que os resultados futuros sejam positivos.

Ressalta-se também a relevância do horizonte de tempo considerado no planejamento das empresas para que elas incluam o meio ambiente e a "justiça social" como variáveis relevantes para a sua sustentabilidade, como por exemplo, tem sido o caso de empresas brasileiras como: Vale do Rio Doce, Petrobras, Gerdau, Companhia Siderúrgica Tubarão, Companhia Siderúrgica Nacional, dentre inúmeras outras.

\section{CONCLUSÃO}

Ao longo deste capítulo apresentou-se que a postura empresarial é relevante para o desenvolvimento sustentável e que este pode contribuir para a melhor competitividade empresarial, na medida em que pode ser o elemento indutor de redução de respectivos custos e riscos econômicos.

Os instrumentos para apoiar a implantação da gestão ambiental voluntária, tais como a certificação pela norma ISO 14001, o PmaisL, a A3P, a premiação por desempenho e o benchmark empresarial, a criação de novos mercados como o de seqüestro de carbono e/ou o de reciclagem e re-uso de materiais, têm estimulado melhoria no desempenho ambiental e social empresarial no País, que por sua vez, estimula a introdução de tecnologias de controle ambiental e social, bem como de eficiência no processo produtivo, além da inovação tecnológica.

Os estudos de caso que apresentam os resultados da introdução da PmaisL em empresas no Brasil mostram que a implantação de medidas de controle/mitigação da poluição emitida por empresas, resultou em redução de custos ou em retorno econômico do investimento realizado (BARATA, 2006). Mas isto não pode ser generalizado, pois existem casos em que em face ao elevado custo do equipamento necessário para o controle ou a mitigação da degradação ambiental, o empresário só investirá em redução do impacto ambiental se a empresa tiver um horizonte de planejamento que possibilite evidenciar que o elevado custo do presente poderá contribuir no futuro para evitar maiores custos, bem como para manter a respectiva competitividade; ou se esta for uma demanda da parte interessada estratégica. Dentre as quais: (1) o governo, responsável pelo cumprimento do marco regulatório do País; (2) a comunidade, estabelecida em área de influência, direta e indireta, das atividades da empresa; (3) clientes e consumidores; (4) fornecedores; (5) investidores; (6) força de trabalho; (7) acionistas; (8) concorrentes; (9) empresas parceiras e outros.

A influência das diferentes partes interessadas sobre o desempenho ambiental e social da empresa varia de acordo com a respectiva atuação e seu potencial impacto sobre a rentabilidade e competitividade empresarial, mas governo e comunidade são sempre partes interessadas estratégicas. A comunidade esclarecida poderá melhor influenciar no desenho e cumprimento de um marco regulatório adequado ao desenvolvimento sustentável local, regional e global. Caberá ao governo, a exigência de cumprimento do mesmo. Ambos poderão influenciar as demais partes interessadas, na medida em que 
tornem públicos os impactos ambientais e sociais positivos e negativos das empresas, ou que exijam o cumprimento dos respectivos requisitos legais.

O conhecimento quanto aos impactos ambientais e sociais, negativos e positivos, inerentes a uma determinada atividade, necessita ser efetivamente conhecido para que se possa estabelecer e aplicar com eficiência e eficácia o marco regulatório em todas as áreas do País. Esforços, embora recentes e ainda tímidos, têm sido realizados no País para que se amplie o conhecimento científico sobre os reais impactos de algumas atividades produtivas. Parte destes esforços é financiada por empresas interessadas em evitar gastos futuros com remediações e compensações à sociedade pelo dano já imposto ou por identificar que isto poderá lhes resultar em vantagem competitiva. Entretanto, o conhecimento adquirido nem sempre é disseminado e fica restrito a alguns segmentos sociais.

Na atual década, a mídia no País tem contribuído para informar a sociedade de alguns riscos ambientais sob os quais estamos submetidos. A identificação de que o bom padrão de desempenho ambiental e social pode angariar adeptos a produtos e serviços de determinados segmentos produtivos, têm motivado em alguns casos para que estes apresentem na mídia as suas "boas práticas". Não obstante, é necessário avaliar a empresa e os respectivos produtos e serviços em todo o seu ciclo de vida, pois ainda se percebe no País, empresas que têm unidades certificadas e apresentam-se como ambientalmente responsáveis, mas que realizam em algumas de suas unidades práticas danosas ao ambeinte. Como evitar tais práticas?

Através do investimento maciço em conhecimento das inter-relações dos ecossistemas e das possíveis soluções de baixo custo econômico que contribuam para a melhoria do desempenho ambiental empresarial, bem como da disseminação do conhecimento adquirido a todas as partes interessadas em linguagem apropriada a seu entendiemnto e aprendizado. A atuação da mídia e também a ampliação da educação ambiental nas escolas, universidades e cursos técnicos também são essenciais para que o conhecimento sobre a complexidade das relações entre os sistemas vivos e potenciais impactos de atividades humanas sejam ampliados e contribuam para que as partes interessadas possam influenciar positivamente no desempenho ambiental e social das empresas.

Conclui-se que a atuação da sociedade civil e do governo, assim como a postura de empresas concorrentes ou parceiras (que atuam ao longo de mesma cadeia produtiva ou são a esta indiretamente associada) são relevantes para induzir o comportamento responsável do setor empresarial e propõe-se que seja dada ênfase a educação ambiental, que contribua para que a transição de uma economia baseada em bens seja substituída por uma economia de serviço e fluxo, cujo foco está mais voltado para o bem-estar social.

A educação ambiental desponta como possibilidade de fornecer instrumentos para a participação social, abrindo possibilidades de novos conhecimentos, metodologias e habilidades numa perspectiva interdisciplinar. $\mathrm{Na}$ medida em que ela não se resume apenas a educação de princípios da ecologia, mas capacita pessoas nos princípios da ética, equidade, e os prepara para uma revisão de padrão de consumo e qualidade de vida, ela representa um instrumento essencial para a sustentabilidade.

Conforme CARVALHO (1993, p. 40): Para construirmos valores mais solidários e garantirmos o direito à vida, para nossa e para aquelas que virão, não basta ser amigo das árvores e dos animais, é preciso criar práticas sociais efetivamente democráticas e 
solidárias na relação entre os homens.

\section{BIBLIOGRAFIA}

ASSOCIAÇÃO BRASILEIRA DE EMPRESAS DE TRATAMENTO DE RESÍDUOS (ABETRE). Perfil do setor de tratamento de resíduos e serviços ambientais. São Paulo: ABETRE, 2006.

BARATA, M.M.L et all. A ecoeficiência aplicada no setor público no Brasil: sua contribuição no setor de saneamento. Caderno de Estudos Avançados. Rio de Janeiro: IOC/Fiocruz. Volume 3, número 2. 2006.

Auditoria Ambiental no Brasil - Uma nova ferramenta de gestão empresarial. Dissertação (Mestrado). Rio de Janeiro: COPPE/UFRJ, 1995.

CAIRnCROSS, F. Meio Ambiente, Custos e Benefícios. Rio de Janeiro: Editora Nobel, 1992.

CAPRA, F. Alfabetização ecológica: o desafio para o século 21. In: TRIGUEIRO. Meio Ambiente no século 21. Rio de Janeiro: Sextante: 2003.

As conexões ocultas: ciência para uma vida sustentável. São Paulo: Editora Pensamento Cultrix, 2002.

COMISSÃO MUNDIAL SOBRE MEIO AMBIENTE E DESENVOLVIMENTO (CMMAD). Nosso Futuro Comum. Rio de Janeiro: Fundação Getúlio Vargas, 1988.

DIAMOND, J. Como as sociedades escolhem o fracasso ou o sucesso. Rio de Janeiro: Editora Record: 2006.

FREEMAN, E. R. Strategic Management: A Stakeholder Approach. Boston: Pitman Publishing Inc., 1984

INSTITUTO NACIONAL DE METROLOGIA, NORMALIZAÇÃO E QUALIDADE (INMETRO). Investimento em controle ambiental das indústrias no Brasil. Rio de Janeiro: INMETRO - diretoria de pesquisa: 2007.

LEMOS, H. M. Competitividade, Meio Ambiente e Responsabilidade Social Corporativa. Apostilas distribuídas no curso "Master Business on Environmntal", COPPE/UFRJ. Rio de Janeiro, 2000.

LIMA/PPE/COPPE/UFRJ. Implementação do Plano de Responsabilidade Socioambiental: Módulos 1 e 4. Relatório do projeto PPE-8805. Rio de Janeiro: Fundação COPPETEC, 2007.

LUSTOSA, D. Relatório da Rede Brasileira de PmaisL. SEBRAE, 2003.

MINISTÉRIO DO MEIO AMBIENTE (MMA). Agenda Ambiental na Administração Pública. Brasília: Ministério do Meio Ambiente, 2006.

REIS, L.B.; CARVALHO,C.E.; GALVÃO, L.C.R. e UDAETA, M.E.M..Internalização 114 das externalidades no Planejamento energético através do ACV e do ACC. In: Revista Brasileira de Energia. Volume 8, número 2, pp. 113-134. 2001. 
RESOLUÇÃO CONAMA no23 de 07/12/94

RESOLUÇÃO CONAMA no 237 de 10/12/97

RODRIGUES, M.C.P. Ação social das empresas privadas: como avaliar resultados?: a metodologia EP²ASE. Rio de Janeiro: FGV, 2005.

SALAMA, P. e DESTREMAU,B. 0 tamanho da pobreza: economia política da distribuição de renda. Rio de Janeiro: Garamond, 1999.

VEIGA, J.E. Desenvolvimento sustentável: o desafio do século XXI. Rio de Janeiro: Garamond, 2006 2a edição.

www.inmetro.gov.br ., último acesso em 16 de julho de 2007.

www.pmaisl.com.br $/ \mathrm{mambo} /$ index.php?option=com content\&task=view\&id=18\&Itemid= 47. Acesso em 6 de julho de 2007.

www.mma.gov.br/index.php?ido=conteudo.monta\&idEstrutura=36 . Acesso em 2 de agosto de 2007.

http://www.ethos.org.br. Acesso em 24 de Março de 2006 apud Souza, 2006.

http://www.sustainability-index.com . Acesso em 14 de Junho de 2006 apud Souza, 2006 